\title{
A Web-Based Serious Game for Health to Reduce Perioperative Anxiety and Pain in Children (CliniPup): Pilot Randomized Controlled Trial
}

Connor Buffel $^{1}$, BSc, MBT; June van Aalst ${ }^{2}$, BSc, MSc; Anne-Marie Bangels ${ }^{3}$, BSc; Jaan Toelen ${ }^{3}$, MD, PhD; Karel Allegaert $^{3,4}$, MD, PhD; Sarah Verschueren ${ }^{5}$, PhD; Geert Vander Stichele ${ }^{5}$, MSc, PharmD

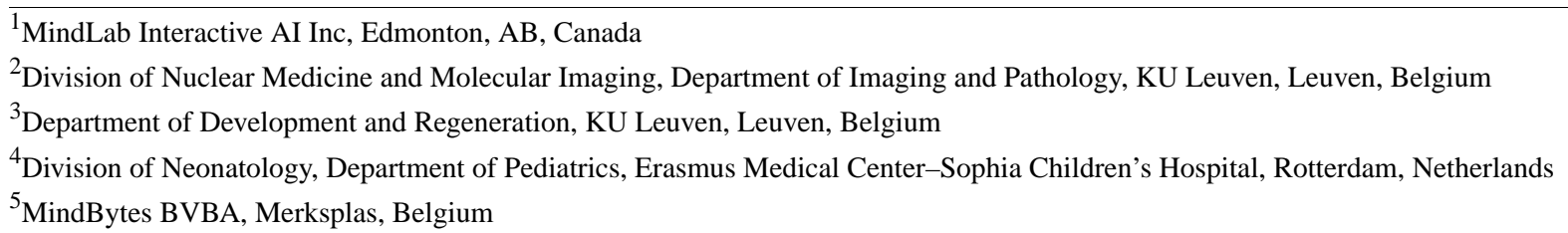

\section{Corresponding Author:}

Sarah Verschueren, $\mathrm{PhD}$

MindBytes BVBA

Schoondreef 7

Merksplas,

Belgium

Phone: 32476753516

Email: sarahverschueren@hotmail.com

\begin{abstract}
Background: As pediatric ambulatory surgeries are rising and existing methods to reduce perioperative anxiety and pain are lacking in this population, a serious game for health (SGH), CliniPup, was developed to address this unmet need. CliniPup was generated using the SERES framework for serious game development.

Objective: The goal of the research was to clinically evaluate CliniPup as an adjunct therapy to existing pharmacological interventions aimed at reducing perioperative anxiety and pain in children undergoing ambulatory surgery.

Methods: CliniPup was evaluated in a prospective randomized controlled pilot trial in 20 children aged 6 to 10 years who underwent elective surgery and their parents. Study participants were randomly assigned to the test $(n=12)$ or control group $(n=8)$. Children in the test group played CliniPup 2 days prior to surgery, and children in the control group received standard of care. On the day of surgery, pediatric anxiety was measured with the modified Yale Preoperative Anxiety Scale and parental anxiety was assessed with the State-Trait Anxiety Inventory. Pediatric postoperative pain was assessed by the Wong-Baker Faces Pain Rating Scale. Child and parent user experience and satisfaction were also evaluated in the test group using structured questionnaires.

Results: Despite the small sample, preoperative anxiety scores were significantly lower $(P=.01)$ in children who played CliniPup prior to surgery compared to controls. Parental preoperative anxiety scores were also lower in the test group $(P=.10)$ but did not reach significance. No significant differences were observed in postoperative pain scores between groups $(P=.54)$. The evaluation of user experience and satisfaction revealed that both children and parents were satisfied with CliniPup and would recommend the game to peers.
\end{abstract}

Conclusions: Results of the pilot trial introduce CliniPup as a potentially effective and attractive adjunct therapy to reduce preoperative anxiety in children undergoing ambulatory surgery with a trend toward positive impact on parental preoperative anxiety. These results support the use of the SERES framework to generate an evidence-based SGH that results in positive health outcomes for patients. Based on these preliminary findings, we propose a research agenda to further develop and investigate this tool.

Trial Registration: ClinicalTrials.gov NCT038744442; https://clinicaltrials.gov/ct2/show/NCT03874442 (Archived by WebCite at http://www.webcitation.org/78KZab8qc)

(JMIR Serious Games 2019;7(2):e12431) doi: 10.2196/12431 


\section{KEYWORDS}

serious games for health; behavior change; perioperative pain; perioperative anxiety; pediatric; ambulatory surgery

\section{Introduction}

\section{Background}

Ambulatory surgeries are increasing at a significant rate, and procedures are associated with high levels of perioperative pain and anxiety [1-4]. This is particularly true in children, with $40 \%$ to $60 \%$ experiencing high levels of anxiety on the day of surgery, and more than $30 \%$ experiencing moderate to severe postoperative pain $[1,2,4,5]$. This leads to both acute and long-term physical and psychosocial outcomes [5-7].

The current management of perioperative anxiety and pain is particularly difficult in children and is considered inadequate due to the limitations of existing interventions $[6,8,9]$. Specifically, the use of alternative nonpharmacological interventions to reduce anxiety is limited by cost, time restrictions, availability, and efficacy $[6,7,9,10]$. In addition, pharmacological interventions are limited by adverse effects, inconsistent prescribing practices, and poor parental assessment and understanding of pain [11-18]. Therefore there is a need to develop additional interventions to better address perioperative anxiety and pain.

Digital interventions have the potential to prepare, educate, and/or distract children, which may result in health outcome benefits such as reductions in perioperative anxiety [7,19-22]. MindBytes is focused on empowering and educating individuals using interactive digital tools and developed a serious game for health (SGH), CliniPup, to prepare children and their parents for surgery [23].

CliniPup has the potential to address limitations of existing nonpharmacological interventions as it is relatively low cost, requires minimal time and resources, and could be widely deployed. Moreover, it has the potential for synergy as an adjunct to pharmacological interventions by preparing parents for postoperative pain management. In addition, it has the potential to address gaps of distraction techniques by preparing both children and parents in a fun and intuitive manner [23]. Although it is clear that preparing both children and parents is vital, this research focused mainly on children due to the challenge of addressing child and parental learning objectives in a single $\mathrm{SGH}[6,7,13,24]$.

This study evaluated CliniPup's usability, safety, and effectiveness in a pilot trial with the target population.

\section{Objective}

The objective of this research was to evaluate CliniPup's usability and clinical impact in comparison to the standard of care in a pilot trial.

\section{Methods}

\section{Pilot Trial}

CliniPup's impact on perioperative pain and anxiety in children was evaluated in a pilot clinical trial with 20 children aged 6 to 10 years who were with their parents and undergoing ambulatory surgery. Several secondary outcomes were also evaluated in the trial such as parental anxiety and SGH usability.

\section{Trial Design}

The study was a prospective, randomized, 2-armed controlled pilot study conducted at 2 institutions in Belgium (RZ Tienen, Campus Mariendal and RZ Tienen, Medisch Centrum Aarschot) from April to May 2016. Study participants were assigned to a test group $(n=12)$ or a control group $(n=8)$ using a block randomization technique dependent on the week of contact by the researcher (eg, one week participants were randomized to test group and the following week, participants were randomized to the control group). Children in the test group played CliniPup 2 days prior to surgery. On the day of surgery, children's anxiety was measured with the modified Yale Preoperative Anxiety Scale (mYPAS) and parental anxiety was assessed with the State-Trait Anxiety Inventory (STAI). Pediatric postoperative pain was assessed by means of the Wong-Baker Faces Pain Rating Scale (WBFPRS). The testing protocol for the control subjects only differed in that they did not receive an intervention, whereas the assessments remained the same (except for the Likert scale; Figure 1). 
Figure 1. Study design flowchart. STAI: State-Trait Anxiety Inventory; mYPAS: modified Yale Preoperative Anxiety Scale; WBFPRS: Wong-Baker Faces Pain Rating Scale.

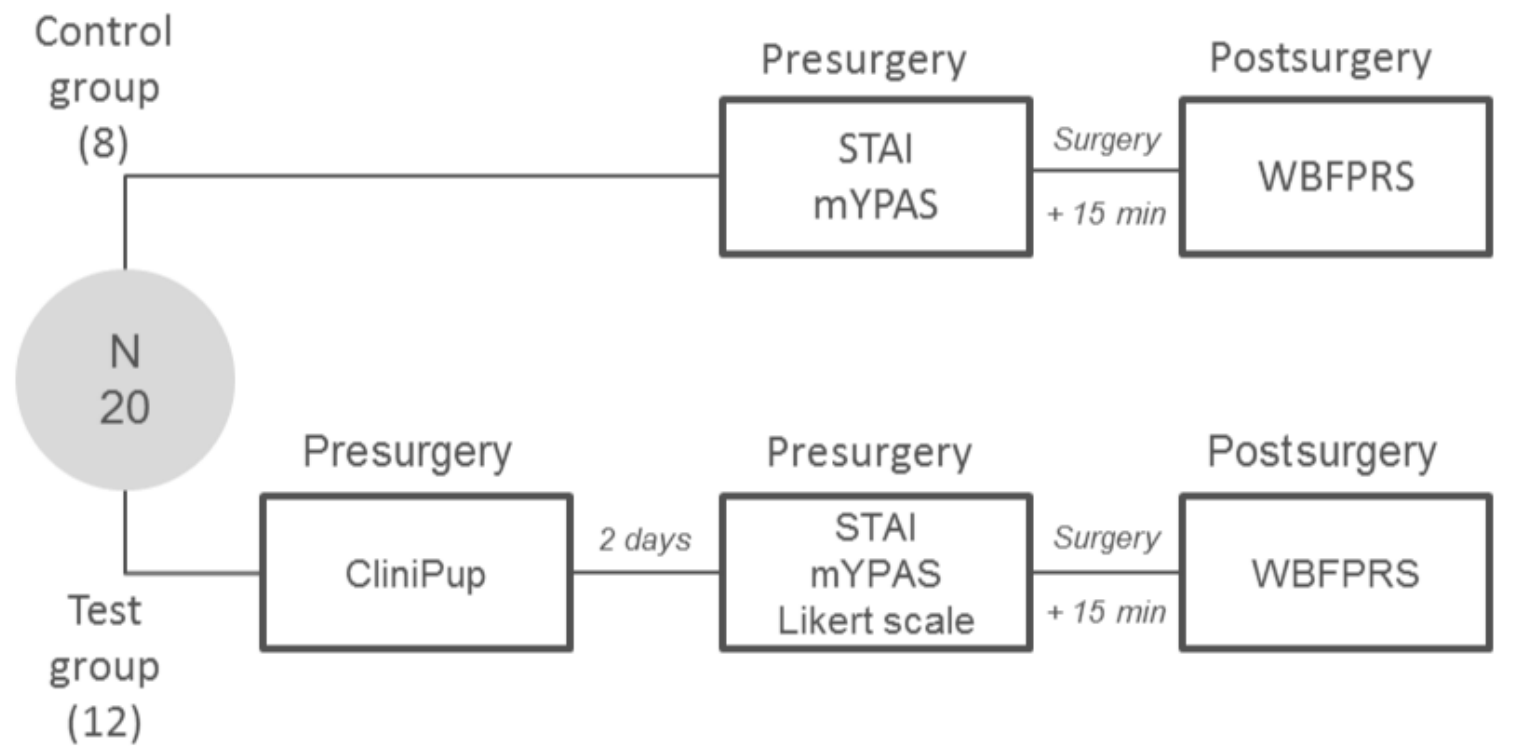

\section{Participants}

A total of 32 children were contacted for inclusion in the study from March to April 2016 from 2 centers in Belgium. Every other week the subjects were included in either the test group or the control group. Eligible participants and their parents for the test group were recruited 2 days before surgery through patient lists of scheduled operations in the surgical day center of RZ Tienen or Medisch Centrum Aarschot in consultation with the doctors. Two days before surgery, parents were contacted by telephone and invited to participate with their child in the study. If they were interested in participation, an email was sent with a link to the CliniPup game. Parents were asked to play the game together with their child. Study information for the parent and child and consent and assent papers were sent via email.

Participants in the control group were recruited at the hospital prior to surgery. Inclusion criteria were (1) aged 6 to 10 years, (2) parents have signed an informed consent, (3) children have given assent, and (4) children and parents understand and speak the Dutch language. Exclusion criteria were (1) children who have been diagnosed with a mental illness, (2) children who have been diagnosed with a developmental delay, (3) children who have a history of an affective disorder, and (4) children with an American Society of Anesthesiology physical status greater than II.

Written informed consent was obtained from 20 parents and assent from 20 children included in the study. The Medical Ethics Committees of UZ Leuven, KU Leuven, and RZ Tienen in Belgium approved all study procedures in advance (study number S58541).

\section{Interventions}

The test group accessed CliniPup online and played at home 2 days prior to surgery, and the control group received no intervention (ie, received standard of care).

\section{Outcomes}

\section{Primary Outcomes}

\section{Preoperative Anxiety}

After registration and admission at the hospital, study information was explained to the parent and the child. After signing the consent and assent papers, the preoperative anxiety of the child was measured by the researcher using the mYPAS. The mYPAS is a validated structural observational scale consisting of 27 items in 5 domains (activity, vocalizations, emotional expressivity, state of arousal, and use of parent) of behavior indicating anxiety in young children [25]. After the assessment, a total adjusted score ([activity score/4 + vocalizations score $/ 4$ + emotional expressivity score $/ 4$ + state of arousal/4 + use of parent score/4] * 100/5) was calculated [25].

Aligned with the institution guidelines, some of the children were given premedication. However, assessment of preoperative anxiety was always completed before the administration of the premedication.

\section{Postoperative Pain}

Children were asked to scale their pain using the WBFPRS once they were awake and responsive (15 minutes after they were back in their room). The WBFPRS is used to assess pain in children and help them communicate about it [26]. The WBFPRS, which is an auto-evaluation scale, has six faces representing no pain (0) to worst pain ever (5) [27].

\section{Secondary Outcomes}

\section{Parental Preoperative Anxiety}

After signing the consent and assent papers, parental anxiety was assessed with the STAI, a widely used self-report anxiety-assessment instrument [28]. There are 2 subscales: State Anxiety Scale and Trait Anxiety Scale. The State Anxiety Scale evaluates the current state of anxiety using items that measure 
feelings of apprehension, nervousness, tension, worry, and so on. The Trait Anxiety Scale evaluates relatively stable aspects of anxiety including general states confidence, calmness, and security. A total STAI score can be calculated by adding all scores. For the anxiety-absent items, the scores should be reversed (19 items of the total 40) [29].

\section{User Experience and Satisfaction}

In the case of the test group, user experience and satisfaction was also assessed through a questionnaire where parents and children completed a Likert scale for each question. Additionally, parents were asked to what extent they would recommend CliniPup to peers, and a net promoter score (NPS) was calculated [30].

\section{Statistical Analysis}

A descriptive analysis was performed on the results. No formal power calculation was used. In addition, the children were divided in this study into 2 groups, a test group and a control group. A Fisher exact test was used to assess if gender, previous surgery, and the use of premedication were significantly different between the two groups. Additionally, a Wilcoxon rank-sum test (a nonparametric analogue of the $t$ test for two independent samples) was performed to test if the distribution of age was the same across both groups. An independent $t$ test was used to determine if there were significant differences in parental anxiety scores between the two groups. A Mann-Whitney U test was used to determine if the preoperative anxiety scores and the postoperative pain scores differed significantly between the control and test group. All statistical analyses were performed using SPSS version 23.0 statistical software (IBM Corp) and were 2-sided with a level of significance of .05 .

\section{Results}

\section{Patient Flow}

Every child aged between 6 and 10 years who met the inclusion criteria was invited to enter the study. In total, 32 children were contacted. After exclusions due to language barriers and no interest in participation, 20 children were recruited. Twelve children were included in the test group and 8 in the control group. In the test group, 8 children were scheduled for tympanostomy tube placement, 2 for adenoidectomy, and 2 for narcodontia (dental care that takes place under general anesthesia). In the control group, 3 children were scheduled for tympanostomy tube placement, 3 for narcodontia, 1 for adenoidectomy, and 1 for adenoidectomy in combination with tympanostomy tube placement (Figure 2).

\section{Baseline Characteristics}

Baseline characteristics of study participants are shown in Table 1. There were no significant differences in age, gender, premedication use, and previous surgery experience between the two groups. The distribution of age and gender was the same across the two groups.

\section{Primary Outcomes}

\section{Preoperative Anxiety}

The researchers measured preoperative anxiety in study participants with the mYPAS observational scale. The mean total adjusted mYPAS score showed a significant difference between the control group and test group (51.88 [SD 15.57] vs 31.67 [SD 7.79], respectively; $P=.01$; Figure 3). This demonstrated that children who played CliniPup before surgery were less anxious than children who did not play CliniPup. No significant correlation was found between the number of times children played CliniPup (1.83 [SD 1.03]) and the total adjusted mYPAS score.

Figure 2. Patient flow diagram.

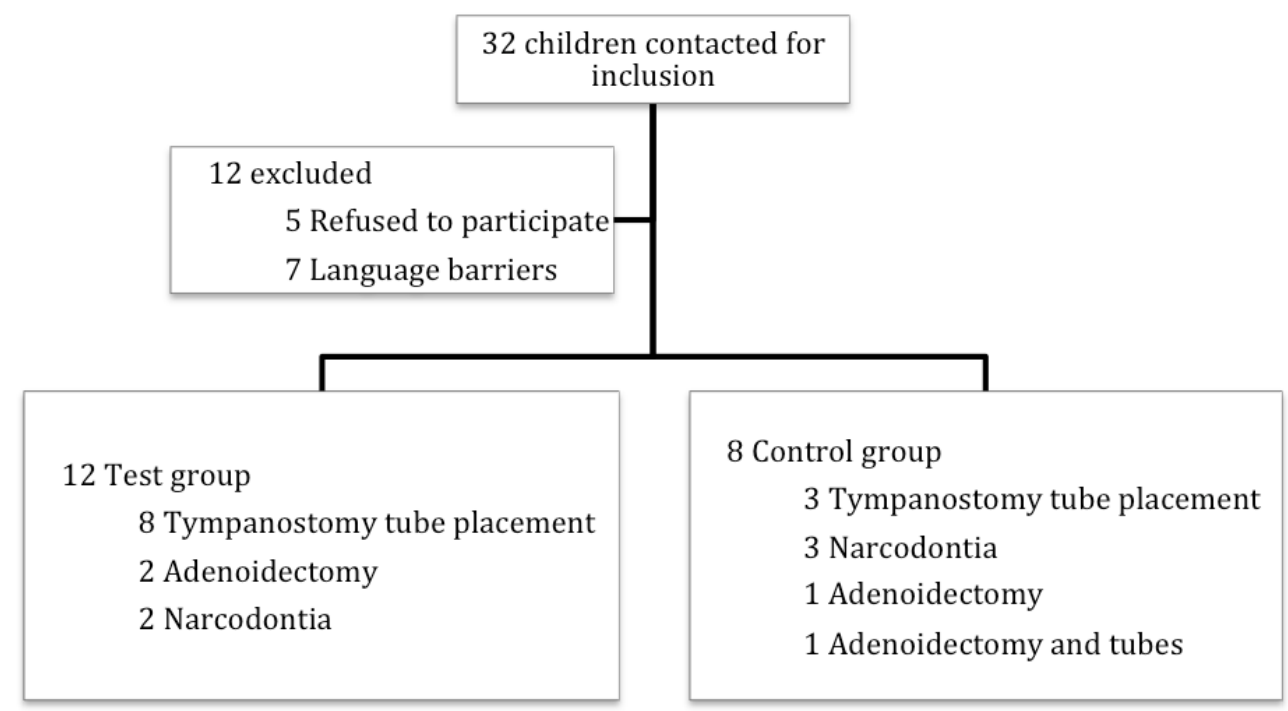


Table 1. Baseline study participant characteristics.

\begin{tabular}{llll}
\hline Child characteristic & Control group (n=8) & Test group (n=12) & $P$ value \\
\hline Age in years, mean (SD) & $6.87(0.93)$ & $7.49(1.82)$ & .52 \\
Gender, male, n (\%) & $3(38)$ & $6(50)$ & .67 \\
Previous surgery, yes, n (\%) & $2(25)$ & $9(75)$ & .07 \\
Premedication with midazolam, yes, n (\%) & $5(63)$ & $2(17)$ & .06 \\
Number of times CliniPup was played, mean (SD) & $-{ }^{\mathrm{a}}$ & $1.83(1.03)$ & - \\
Surgery type, $\mathbf{n}(\%)$ & & & - \\
$\quad$ Tympanostomy tube placement & $3(38)$ & $8(67)$ & - \\
$\quad$ Adenoidectomy & $1(13)$ & $2(17)$ & - \\
$\quad$ Narcodontia & $3(38)$ & $2(17)$ & - \\
Adenoidectomy and tubes & $1(13)$ & $0(0)$ & \\
\hline
\end{tabular}

${ }^{\mathrm{a}}$ Not applicable.

Figure 3. Child preoperative anxiety. mYPAS: modified Yale Preoperative Anxiety Scale.

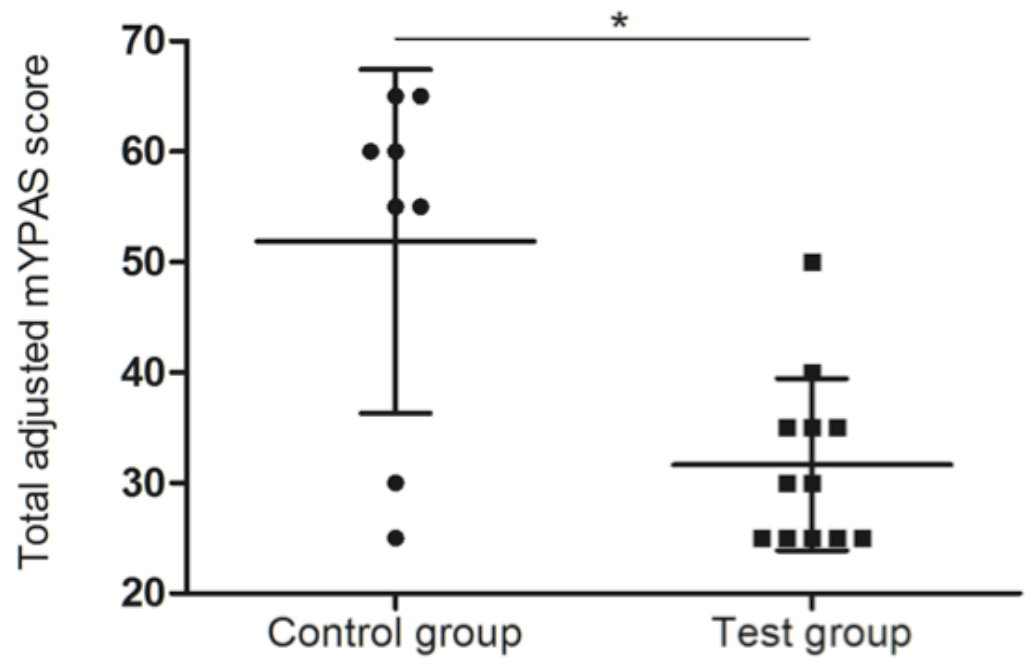

\section{Postoperative Pain}

Postoperative pain in study participants was measured with the WBFPRS scale 15 minutes postoperatively. No significant differences were shown in the analysis of the postoperative pain scores between the control and test group (3.50 [SD 2.77] vs 4.18 [SD 2.33], respectively; $P=.54$; Figure 4).

\section{Secondary Outcomes}

\section{Parental Preoperative Anxiety}

Parental preoperative anxiety was measured with the STAI completed by the parent before surgery. No significant difference was found between the control group and test group (41.13 [SD 7.70] vs 34.09 [SD 10.00], respectively; $P=.10$; Figure 5).

\section{User Experience and Satisfaction}

\section{Children}

To evaluate CliniPup, we asked children to complete a Likert scale questionnaire. Sixty-seven percent (8/12) of children liked CliniPup very much, 17\% (2/12) of children liked CliniPup at least somewhat, and $17 \%$ (2/12) were undecided. Children were also asked if they learned anything by playing CliniPup. Forty-two percent (5/12) learned very much, 33\% (4/12) learned somewhat, $20 \%(2 / 12)$ were undecided, and $8 \%$ (1/12) learned nothing at all. In summary, $75 \%(9 / 12)$ of children learned somewhat or very much from playing CliniPup.

\section{Parents}

One parent of each child (the parent who played CliniPup together with their child) completed the Likert scale questionnaire and provided information on the extent with which they would recommend CliniPup to peers. 
Figure 4. Child postoperative pain. WBFPR: Wong-Baker Faces Pain Rating Scale.

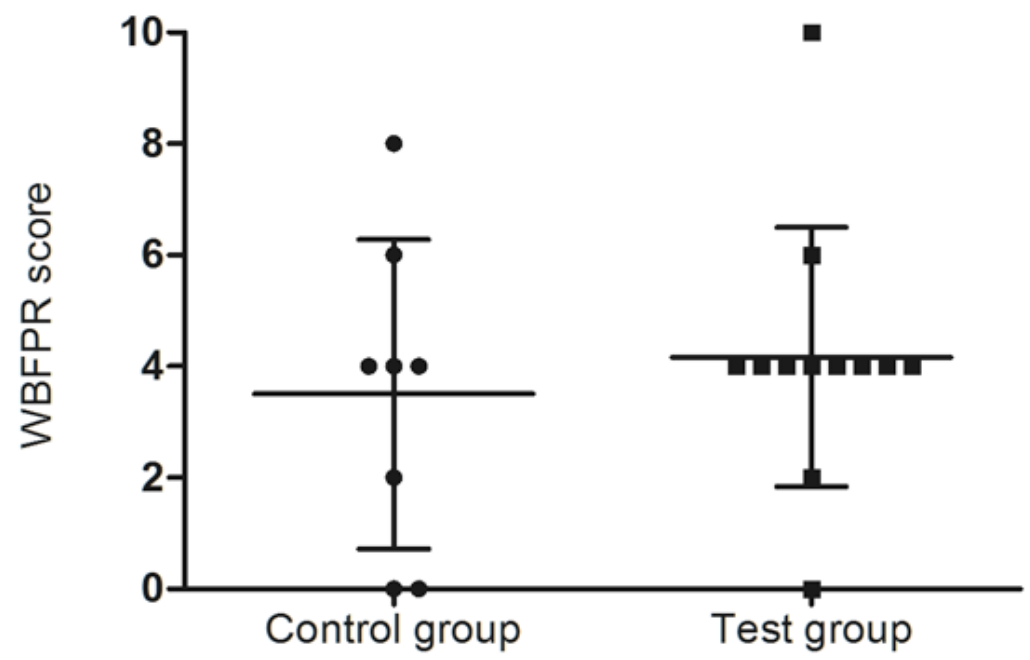

Figure 5. Parental preoperative anxiety. STAI: State-Trait Anxiety Inventory.

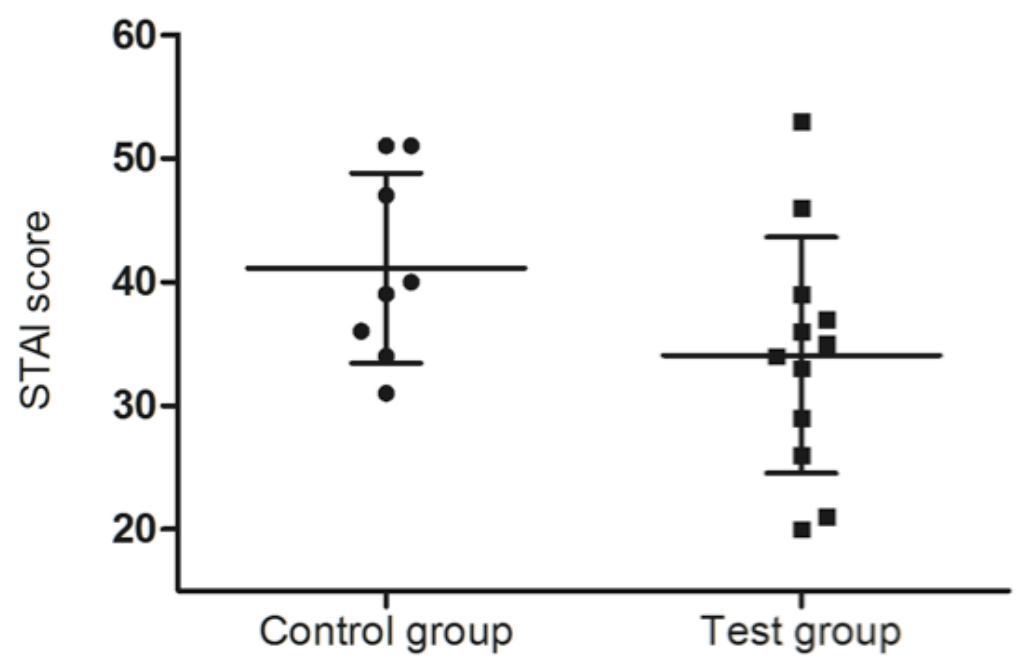

Eighty-three percent (9/12) of the parents strongly agreed that "CliniPup was clear; my child understood everything." Fifty-eight percent (7/12) of parents strongly agreed and $42 \%$ (5/12) agreed that "CliniPup helped to prepare my child for surgery." Forty-two percent (5/12) of parents strongly agreed and 50\% (6/12) agreed that "I received useful information by playing CliniPup together." Additionally, 42\% (5/12) disagreed, and $25 \%$ (3/12) strongly disagreed that "I had to give additional information to my child." Lastly, 17\% (2/12) strongly agreed, $33 \%(4 / 12)$ agreed, and 50\% (6/12) did not disagree nor agree that they would like something similar to prepare themselves for the surgery of their children.

When asked on a scale from 0 to 10 (very unlikely to very likely) to what extent they would recommend CliniPup to their friends/family/colleagues, $42 \%$ (5/12) of parents gave a 10, 25\% $(3 / 12)$ gave a $9,17 \%(2 / 12)$ gave an 8 , and $17 \%(2 / 12)$ gave a 7. These results correspond to an NPS of $67 \%$.

\section{Discussion}

\section{Principal Findings}

The findings of this pilot study suggest that the use of CliniPup, an SGH, may be an effective adjuvant intervention to contemporary management of perioperative anxiety and pain in children undergoing ambulatory surgery and their parents. The results of the pilot trial showed that the test group experienced significantly less preoperative anxiety, as measured by the mYPAS scale, than the control group (Figure 3). In contrast, there were no between-group differences in postoperative pain, as measured by WBFPRS, immediately (15 minutes) after surgery (Figure 4). This was not surprising given that operations (tympanostomy tube placement, adenoidectomy, narcodontia, and adenoidectomy in combination with tube placement) were unequally distributed between the groups. This makes it difficult for a fair and representative comparison of postoperative pain scores between groups.

Considering the secondary outcomes, parents of children in the test group experienced equivalent, with a trend toward reduced, 
preoperative anxiety compared to parents of children in the control group (Figure 5). In addition to the clinical outcomes, the study determined that the majority of children enjoyed playing CliniPup very much and learned a lot by playing CliniPup. Parents agreed with this sentiment as the majority agreed that CliniPup helped their child prepare for surgery. Moreover, CliniPup's NPS was considered excellent, demonstrating that parents were likely to recommend this nonpharmacological intervention to others.

By alleviating anxiety in the home setting prior to surgery, this SGH may address challenges associated with current nonpharmacological interventions such as cost, time requirements, and accessibility and availability $[7,9,10]$. This may, in turn, reduce the long-term psychosocial burden experienced by children with perioperative anxiety and pain $[2,24,31,32]$. CliniPup may also offer the potential to improve economic outcomes by reducing medical resource use and decreasing hospital discharge times [2,24,31-33]. However, this would require more targeted research to confirm.

CliniPup shows the potential to address the unmet need of children in the perioperative setting by offering an effective, inexpensive, accessible, and evidence-based nonpharmacological intervention to reduce perioperative anxiety and pain in children.

The data collected within this pilot trial support the conclusion that an SGH, when developed using a scientific methodology such as the SERES Framework, may be particularly valuable as an intervention to educate and change behavior in health care settings [34]. This may be particularly true for a pediatric population, but the generalizability of the approach implemented also suggests that this method could be applicable in adult populations as well. In addition, it is conceivable that similar interventions could be developed to realize behavior change and impact health outcomes in other fields such as mental health, rare disease, cardiovascular health, oncology, etc.

The results collected in this pilot trial serve as important inputs to be used in subsequent iterations of the SGH. This was, in particular, one of the key objectives of the pilot trial, in that the findings will be used to inform the next steps of trial design and game development.

\section{Limitations}

The results of this study, however, should be considered as preliminary due to the small sample size and methodological limitations (block randomization, nonblind, inactive control group, two study centers, child and surgical characteristics not controlled for, etc) of a pilot trial. Although the findings of this pilot study are promising, further research is required to validate CliniPup's efficacy in a pivotal trial that is adequately powered to detect between group differences. Additionally, it may be prudent to include an active control and further control for child and surgical characteristics to limit potential methodological biases. Moreover, it may be valuable to investigate the mechanistic bases for the observed changes in perioperative anxiety, which may differ from hypothesized theories and could inform clinical practice. Finally, methodological changes or adaptations to the SGH CliniPup should be considered to enhance the potential for addressing postoperative pain in addition to preoperative anxiety. For example, it is logical to theorize that the addition of a supplementary digital tool targeted at parents of children undergoing ambulatory surgery could improve outcomes, as this would explicitly address parental fears, a key determinant of child pain and anxiety [23]. Such a tool has subsequently been developed, and methodological modifications will be integrated into an upcoming pivotal study to also evaluate (behavioral) changes in postoperative pain management at home.

\section{Conclusion}

In summary, the results of the pilot study introduce CliniPup as a potentially effective and attractive adjunct therapy to existing interventions aimed at reducing preoperative anxiety in children undergoing ambulatory surgery. The findings also support the validity of the SERES framework for SGH development with respect to achieving positive health outcomes. The results provide important data to inform subsequent development of the SGH and its future clinical validation. Moreover, based on theories applied in the development of the SGH, supplemental components can be integrated to enhance CliniPup's impact on pediatric perioperative anxiety and pain outcomes. Aligned with this, CliniPup's safety and efficacy should be evaluated further in a pivotal trial of the optimized $\mathrm{SGH}$.

\section{Acknowledgments}

We thank JVA and KA for their work in developing the intervention alongside MindBytes and for carrying out the clinical trial. We thank the clinicians at RZ Tienen, Campus Mariendal and Medisch Centrum Aarschot who were involved in the clinical trial. We thank all children and their parents for their participation in the study. MindBytes was the funding source for the development of CliniPup, and the pilot trial itself represented the partial fulfillment of JVA's thesis for a Master of Biomedical Sciences degree at KU Leuven, Belgium. The funders had no role in the conduct of the study.

\section{Conflicts of Interest}

$\mathrm{SV}$ is a paid consultant for MindBytes, GVS is the founder and CEO of MindBytes and MindLab Interactive AI Inc, and CB is an employee of MindLab Interactive AI Inc and previously served as a paid consultant for MindBytes. JVA, AMB, JT, and KA declare no competing financial interests.

Editorial Notice: This randomized study was only retrospectively registered. The editor granted an exception of ICMJE rules for prospective registration of randomized trials because the risk of bias appears low and the study was considered formative. 
However, readers are advised to carefully assess the validity of any potential explicit or implicit claims related to primary outcomes or effectiveness, as retrospective registration does not prevent authors from changing their outcome measures retrospectively.

\section{Multimedia Appendix 1}

CONSORT - EHEALTH checklist (V 1.6.1).

[PDF File (Adobe PDF File), 598KB-Multimedia Appendix 1]

\section{References}

1. Walther-Larsen S, Aagaard GB, Friis SM, Petersen T, Møller-Sonnergaard J, Rømsing J. Structured intervention for management of pain following day surgery in children. Paediatr Anaesth 2016 Feb;26(2):151-157. [doi: 10.1111/pan.12811] [Medline: 26559643]

2. Litke J, Pikulska A, Wegner T. Management of perioperative stress in children and parents. Part I: the preoperative period. Anaesthesiol Intensive Ther 2012;44(3):165-169 [FREE Full text] [Medline: 23110295]

3. Rabbitts JA, Groenewald CB, Moriarty JP, Flick R. Epidemiology of ambulatory anesthesia for children in the United States: 2006 and 1996. Anesth Analg 2010 Oct;111(4):1011-1015. [doi: 10.1213/ANE.0b013e3181ee8479] [Medline: 20802051]

4. Perrott C, Lee C, Griffiths S, Sury MRJ. Perioperative experiences of anesthesia reported by children and parents. Paediatr Anaesth 2018 Dec;28(2):149-156. [doi: 10.1111/pan.13300] [Medline: 29266767]

5. Linton SJ, Shaw WS. Impact of psychological factors in the experience of pain. Phys Ther 2011 May;91(5):700-711. [doi: 10.2522/ptj.20100330] [Medline: 21451097]

6. Fortier MA, Kain ZN. Treating perioperative anxiety and pain in children: a tailored and innovative approach. Paediatr Anaesth 2015 Jan;25(1):27-35 [FREE Full text] [doi: 10.1111/pan.12546] [Medline: 25266082]

7. Banchs RJ, Lerman J. Preoperative anxiety management, emergence delirium, and postoperative behavior. Anesthesiol Clin 2014 Mar;32(1):1-23. [doi: 10.1016/j.anclin.2013.10.011] [Medline: 24491647]

8. Khan KA, Weisman SJ. Nonpharmacologic pain management strategies in the pediatric emergency department. Clin Pediatr Emerg Med 2007 Dec;8(4):240-247. [doi: 10.1016/j.cpem.2007.08.008]

9. Perry JN, Hooper VD, Masiongale J. Reduction of preoperative anxiety in pediatric surgery patients using age-appropriate teaching interventions. J Perianesth Nurs 2012 Apr;27(2):69-81. [doi: 10.1016/j.jopan.2012.01.003] [Medline: 22443919]

10. Copanitsanou P, Valkeapää K. Effects of education of paediatric patients undergoing elective surgical procedures on their anxiety: a systematic review. J Clin Nurs 2014 Apr;23(7-8):940-954. [doi: 10.1111/jocn.12187] [Medline: 23581540]

11. Lovich-Sapola J, Smith CE, Brandt CP. Postoperative pain control. Surg Clin North Am 2015 Apr;95(2):301-318. [doi: 10.1016/j.suc.2014.10.002] [Medline: 25814108]

12. Fletcher MC, Spera JF. Management of acute postoperative pain after oral surgery. Dent Clin North Am 2012 Jan;56(1):95-111. [doi: 10.1016/j.cden.2011.09.001] [Medline: 22117944]

13. Howard D, Davis KF, Phillips E, Ryan E, Scalford D, Flynn-Roth R, et al. Pain management for pediatric tonsillectomy: an integrative review through the perioperative and home experience. J Spec Pediatr Nurs 2014 Jan;19(1):5-16. [doi: 10.1111/jspn.12048] [Medline: 24393224]

14. Lauder G, Emmott A. Confronting the challenges of effective pain management in children following tonsillectomy. Int $\mathbf{J}$ Pediatr Otorhinolaryngol 2014 Nov;78(11):1813-1827. [doi: 10.1016/j.ijporl.2014.08.011] [Medline: 25241379]

15. Girard P, Chauvin M, Verleye M. Nefopam analgesia and its role in multimodal analgesia: a review of preclinical and clinical studies. Clin Exp Pharmacol Physiol 2016 Jan;43(1):3-12. [doi: 10.1111/1440-1681.12506] [Medline: 26475417]

16. Finley GA, McGrath PJ, Forward SP, McNeill G, Fitzgerald P. Parents' management of children's pain following 'minor' surgery. Pain 1996 Jan;64(1):83-87. [Medline: 8867249]

17. Dorkham MC, Chalkiadis GA, von Ungern Sternberg BS, Davidson AJ. Effective postoperative pain management in children after ambulatory surgery, with a focus on tonsillectomy: barriers and possible solutions. Paediatr Anaesth 2014 Mar;24(3):239-248. [doi: 10.1111/pan.12327] [Medline: 24330523]

18. Fortier MA, MacLaren JE, Martin SR, Perret-Karimi D, Kain ZN. Pediatric pain after ambulatory surgery: where's the medication? Pediatrics 2009 Oct;124(4):e588-e595. [doi: 10.1542/peds.2008-3529] [Medline: 19736260]

19. Seiden SC, McMullan S, Sequera-Ramos L, De Oliveira GS, Roth A, Rosenblatt A, et al. Tablet-based Interactive Distraction (TBID) vs oral midazolam to minimize perioperative anxiety in pediatric patients: a noninferiority randomized trial. Paediatr Anaesth 2014 Dec;24(12):1217-1223. [doi: 10.1111/pan.12475] [Medline: 25040433]

20. Bul KCM, Kato PM, Van der Oord S, Danckaerts M, Vreeke LJ, Willems A, et al. Behavioral outcome effects of serious gaming as an adjunct to treatment for children with attention-deficit/hyperactivity disorder: a randomized controlled trial. J Med Internet Res 2016 Feb 16;18(2):e26 [FREE Full text] [doi: 10.2196/jmir.5173] [Medline: 26883052]

21. Kato PM, Cole SW, Bradlyn AS, Pollock BH. A video game improves behavioral outcomes in adolescents and young adults with cancer: a randomized trial. Pediatrics 2008 Aug;122(2):e305-e317 [FREE Full text] [doi: 10.1542/peds.2007-3134] [Medline: $\underline{18676516}$ ] 
22. De Queiroz Siqueira M, Tosseti S, Maréchal C, Cogniat B, Berthilier J, Chassard D. Abstract PR237: Effect of iPad tablet on children and parental anxiety during anesthesia. Anesth Analg 2016;123:308-309. [doi: 10.1213/01.ane.0000492635.96205.ee]

23. Verschueren S, Van Aalst J, Bangels AM, Toelen J, Allegaert K, Buffel C, et al. Development of Clinipup, a serious game aimed at reducing perioperative anxiety and pain in children: mixed methods study. JMIR Serious Games 2019. [doi: $\underline{10.2196 / 12429]}$

24. McCann ME, Kain ZN. The management of preoperative anxiety in children: an update. Anesth Analg 2001 Jul;93(1):98-105. [Medline: 11429348]

25. Kain ZN, Mayes LC, Cicchetti DV, Bagnall AL, Finley JD, Hofstadter MB. The Yale Preoperative Anxiety Scale: how does it compare with a gold standard? Anesth Analg 1997 Oct;85(4):783-788. [Medline: 9322455]

26. Wilson M, Helgadóttir H. Patterns of pain and analgesic use in 3- to 7-year-old children after tonsillectomy. Pain Manag Nurs 2006;7:159-166. [Medline: $\underline{17145490}$ ]

27. Kain ZN, Mayes LC, Caldwell-Andrews AA, Karas DE, McClain BC. Preoperative anxiety, postoperative pain, and behavioral recovery in young children undergoing surgery. Pediatrics 2006 Aug;118(2):651-658. [doi: 10.1542/peds.2005-2920] [Medline: $\underline{16882820}$ ]

28. Spielberger C. State-Trait Anxiety Inventory for Adults: Manual. Menlo Park: Mind Garden; 1983.

29. Julian LJ. Measures of anxiety: State-Trait Anxiety Inventory (STAI), Beck Anxiety Inventory (BAI), and Hospital Anxiety and Depression Scale-Anxiety (HADS-A). Arthritis Care Res (Hoboken) 2011 Nov;63 Suppl 11:S467-S472 [FREE Full text] [doi: 10.1002/acr.20561] [Medline: 22588767]

30. Rekhi S. A Practitioner's Guide to Net-Promoter Score (NPS). URL: http://www.sachinrekhi.com/ a-practitioners-guide-to-net-promoter-score-nps [accessed 2018-10-05] [WebCite Cache ID 72wyH0Ov3]

31. Wright KD, Stewart SH, Finley GA, Buffett-Jerrott SE. Prevention and intervention strategies to alleviate preoperative anxiety in children: a critical review. Behav Modif 2007 Jan;31(1):52-79. [doi: 10.1177/0145445506295055] [Medline: 17179531]

32. Taber JM, Leyva B, Persoskie A. Why do people avoid medical care? A qualitative study using national data. J Gen Intern Med 2015 Mar;30(3):290-297 [FREE Full text] [doi: 10.1007/s11606-014-3089-1] [Medline: 25387439]

33. Young KD. Pediatric procedural pain. Ann Emerg Med 2005 Feb;45(2):160-171. [doi: 10.1016/j.annemergmed.2004.09.019] [Medline: 15671974]

34. Verschueren S, Buffel C, Vander Stichele G. Developing theory-driven, evidence-based serious games for health: framework based on research community insights. JMIR Serious Games 2019 May 02;7(2):e11565 [FREE Full text] [doi: 10.2196/11565] [Medline: 31045496]

\section{Abbreviations \\ mYPAS: modified Yale Preoperative Anxiety Scale \\ NPS: net promoter score \\ SGH: serious game for health \\ STAI: State-Trait Anxiety Inventory \\ WBFPRS: Wong-Baker Faces Pain Rating Scale}

Edited by G Eysenbach; submitted 05.10.18; peer-reviewed by A Antoniades, M Bestek; comments to author 03.02.19; revised version
received 29.03.19; accepted 15.04.19; published 01.06.19
Please cite as:
Buffel C, van Aalst J, Bangels AM, Toelen J, Allegaert K, Verschueren S, Vander Stichele G
A Web-Based Serious Game for Health to Reduce Perioperative Anxiety and Pain in Children (CliniPup): Pilot Randomized Controlled
Trial
JMIR Serious Games 2019;7(2):e12431
URL: $\underline{\text { http://games.jmir.org/2019/2/e12431/ }}$
doi: $\underline{10.2196 / 12431}$
PMID: $\underline{31199324}$

(C) Connor Buffel, June van Aalst, Anne-Marie Bangels, Jaan Toelen, Karel Allegaert, Sarah Verschueren, Geert Vander Stichele. Originally published in JMIR Serious Games (http://games.jmir.org), 01.06.2019. This is an open-access article distributed under the terms of the Creative Commons Attribution License (https://creativecommons.org/licenses/by/4.0/), which permits unrestricted use, distribution, and reproduction in any medium, provided the original work, first published in JMIR Serious Games, is properly 
cited. The complete bibliographic information, a link to the original publication on http://games.jmir.org, as well as this copyright and license information must be included. 